\title{
HASAT E KULLIYA WA MASANA (KIDNEY AND BLADDER STONE): A REVIEW
}

\author{
${ }^{1}$ Dr. Zaid Iqbal, ${ }^{2}$ Dr. Abuzar Lari and ${ }^{3}$ Dr. Musarrat Ali \\ ${ }^{1}$ Assistant Professor in Dept. of Anatomy \\ Mohammadia Tibia College\& Assayer Hospital Mansoora Malegaon \\ ${ }^{2}$ Assistant Professor in Dept. of Iaj Bit Tadbeer \\ Mohammadia Tibia College\& Assayer Hospital Mansoora Malegaon \\ ${ }^{3}$ Assistant Professor in Dept. of Ilmul Saidla \\ Mohammadia Tibia College\& Assayer Hospital Mansoora Malegaon
}

\section{Review Paper}

Received: 10.07.2021

Revised: 15.07.2021

Accepted: 22.07.2021

\section{ABSTRACT}

In Unani system of medicine renal stone named as Hasat e Kulliya (kidney stones), Hasat e halib (uretric stones), Hasat e masana (bladder stone). Kidney stones or Renal Calculi (from Latin renes, "kidney" and calculi, "pebbles") are solid structures composed of urinary precipitates and crystals. These stones can range in size from less than a millimeters to few centimeters. From ancient time Greeks have many literatures in which they explained urinary stone disease in detail. The association of stones and putrefaction has been known since Hippocrates (460-377 BC). He was first who described diseases of kidney and symptoms of bladder stones. Many Unani physicians explained surgical procedure and instruments used for removal of stone. The aim of this review to explain renal stone in vision of unani medicine.

No. of Pages: 4

References: 14

Keywords: Hasate kulliya, Hasate Halib, Hasate Masana, Renal stone, ancient medicine.

\section{INTRODUCTION}

\section{History:}

The evidence of urinary calculi has been found in a 7000 years old Egyptian mummy. Ancient Greeks did the first remarkable observation and documentation on urinary stone disease ${ }^{1}$. He first described diseases of the kidney and symptoms of bladder stones. In famous Hippocratic Oath of Medical Ethics for physicians, he underlines "I will not cut for the stone, but will leave this to be done by practitioners of this work." Hippocrates stated that wounds of the bladder were lethal ${ }^{23}$.He discussed both renal and bladder stone also explained the management through plenty of oral fluids and diuretics. The Assyrian Book of Medicine (c. 300 B.C.) includes much of Hippocratic thought and mentioned many prescriptions about flushing out or dissolving renal stones ${ }^{4}$.In Unani system of Medicine the renal calculus is named as "Hasat e Kulliya". Ancient literatures described broadly the pathology, manifestations and treatment of renal stone.

\section{Pathogenesis:}

According to Ali Ibne Abbas Majoosi, renal calculi is formed due to two factors, one is increased Hararat-eGhareezia of kidney and other is Madda (viscid matter). The viscous matter or Ghaleez madda of these calculi derived from viscous Humour \& mucous matter, these matters may be

*Corresponding author:drzami143@gmail.com 
the Phlegmatic or viscous blood or pus. Due to excessive Hararat the Rutoobat of this Madda is dried which after a period of time causes formation of stone. With these if there is constriction in passage of urine or ureter (Majari) causes the accumulation of small crystals and further it forms stone. ${ }^{5}$ 6

\section{According to Nuh bin Mansoor}

Stone formation in kidney and bladder is due to constriction in neck of organs. Due to constriction Hararat is increased, viscid and raw material come towards these organ through urine. If excessive movement (harkat) is present then it converts the raw material into Ghaleez Madda (viscid matter). At beginning small particles are collected, after long period they convert into large stone. ${ }^{6,7}$

\section{According to Ibn Sena}

pathogenesis of kidney and bladder stones are same, both are associated with Sabab e Fayeli. Two things are responsible for development of stones, one is Madda which is ready to accept the property to convert into stone and other is Quwat which convert the Madda into stone. This Madda comes from Balgham orDam. Sometimes the origin of stone formation is injury to the kidney, so the injured area can cause the collection of morbid matter at that site. According to sheikh stone formation needs two things, Ghaleez Madda and stasis of these Ghaleez Madda ${ }^{8}$.

According to Jaleenoos stone formation in kidney is due to injury while the reem (microlith) not excrete and collect in the kidney and formed stone ${ }^{9}$. Pathology behind formation of Stone and microlith is viscid fluid of kidney which collected and dried, forms stone. These Ghaleez Madda dried by the Hararat Shadeed $^{10}$. In case of disturbed kidney function, the improper filtration and excretion of the urine cause the collection of urinary particles in the cavity of the kidney which may cause formation of stone ${ }^{5810}$

\section{Clinical Features:}

According to Majoosi Sign and symptoms of renal stone is frequency and burning micturation with small crest (reeg) in the urine. Patients also having pain in flank region at the site of kidney which is sometime throbbing in nature, lower back pain, numbness in the legs, and dysuria. Patient also having complaint of pain at coccyx region and leg of affected side. The crest in urine may be yellow, red, or brown, and may resemble pomegranate seeds. ${ }^{56}$

Rhazi mentioned the symptoms of calculi as renal pain, incontinence of urine, dysuria. The persons passing sandy precipitate in their urine must have the calculus in his kidneys or in urinary bladder. According to Rhazi when patient having dysuria with severe pain in flank and lower abdomen along with nausea and constipation, itindicates the stone in both kidney. Patient feeling heaviness in the lumbar region or renal area associated with hematuria. Patient also complaint of pain in testis of affected side. ${ }^{(101112)}$

According to Jurjani Signs and symptoms of bladder calculi are dysuria, incomplete voiding of urine, irritation at the root of the urethra, and prurit is over the penis, which compels the patients to rub his hands over the pubic region. The gravel and sediments of bladder calculi are muddy or white. If the pain radiates from the loin towards the pubic area, it is assumed that the calculi are descending in the ureter. Reduced severity of pain in the lumbar region suggests that the renal calculi have reached the bladder. ${ }^{13}$

According to Ibn Sina, renal calculi are soft, small, and usually red in color, whereas bladder calculi are hard, large, and sandy white in color. ${ }^{9}$

Renal calculi cause heaviness in the lumbar region when the intestines are full. The color of urine will be yellow-red. ${ }^{10}$

\section{Diagnosis (Tashkhees)}

In Unani medicine, the atibba' (physicians) valuates nabz (pulse), baul (urine), and baraz (stools) in order to diagnose disease, and when urolithiasis is suspected, the urine is carefully examined to make the final diagnosis. Patients are advised to collect urine overnight in a clean container that must be protected from contaminants. On the following day, the urine is discarded without disturbing any sediment in the container. Red or yellow sediments are diagnostic of urinary stones or gravel. ${ }^{9}$ when urine transforms from thick and viscous to clear and watery, the morbid matter is accumulating in the kidneys and thereby causing stone formation. When black-colored urine appears in the absence of systemic disease or pain in the lumbar region accompanied with abdominal colic, then kidney stones are thought to have formed. $^{13}$

Rufus narrated that if a person is passing black urine without any disease along with pain or without pain, it confirms that after a time period he will develop renal stone especially in elderly person. Iristatalis has narrated that when a person having calculi is passing (crystals) reeg in urine, it predict that the calculi is soft and fragile in nature. So it can be breakdown and excreted with the help of drugs easily while as if the urine of person having calculi is very clear is denoting that the calculi is very hard and unfragiable in nature/ unable to breakdown. Yahoodi cited that person who were passing more amount of salt in their urine are more prone to develop renal calculi. Mohaammed bin Zakariya Razi said, I had observed that children had more amount of salt in their urine. He said, Urinary disturbance accompanied by pain in the loin region during micturation, nausea and constipation suggests that calculi are present in both kidneys. Ahran cited that the color of bladder calculi will be white 
while as the color of renal calculi will be red. He further said that adults always develop renal calculi and children always develop bladder calculi. Ibn Sarabiyun narrated that if the calculi is impacted in a particular area of kidney then pain will be over that particular area. If the stone is moving then in first phase patient will be calm and relax as well as in second phase there will be severe pain. ${ }^{611}$

\section{Treatment}

According to Rufus if a person is passing black urine without any disease along with pain or without pain, it confirms that after a time period he will develop renal stone especially in elderly person, so once should use (diuretics) mudirbol as early as possible. Further he cited that the use of black and offensive clay added with gandhak (sulphur) can act as good antiurolithiatic agent. Ali bin Zain has quoted that renal calculi should be treated with drugs having hot temperament (adviaharra) so that the drug will breakdown the calculi, but the chosen drug should not have excessive hot temperament by which they can cause dryness which may increase stiffness in consistency of calculi. ${ }^{6}$

\section{USOOL ILAJ:}

\section{Water:}

Plenty of oral fluid intake is very good for all stone patients.

\section{Diet:}

Ghaleez Ghiza causes formation of Ghaleez khilt which are responsible for stone formation, so avoid ghaleez ghiza, e.g. concentrated milk, paneer and meat (old camel, old bull, old goat), roasted meat, fish meat and sangeen roti (feteeri, leshdar maida) etc. ${ }^{8}$

\section{Ilaj}

Remove the Asbabe Maddi (causative material), Use of Mufattite Hasatadvia (lithotriptic drugs) and Use of MudirBoladvia (diuretics drugs).

The principle management of renal calculi in Unani medicine is use of Mudirboul (diuretic) and Mufattiti Hissat (lithotriptic) drug to make morbid and abnormal humors easily extractible from the body mainly through the excretory system. ${ }^{11}$

According to Unani scholars the drugs used as Mufattiti Hissat (lithotryptic) must have mild degree of Hararat because severe degree of Hararat makes substances harder. Hence the amount of Hararat in the drugs used as lithotryptic must be less than that required for the formation of stones. The principle used is, any substance or morbid matter which is under the influence of hararat (hot) and yabusat (dry) can be correct by burudat (cold) and rutubat (moist). These mild degree drugs bring equilibrium in the morbid matter or substance and the hararat-eghariziya expels them out of the body. The drugs beneficial are halyun, chana and badam etc. It is also possible that these drugs act due to their constituents and their characteristic features. Drugs which are used to expel the urinary stones must be talkh (bitter) in taste, not very hot and have the property of taqti (cutting, making into small bits). Drugs used for bladder calculi must be slightly hotter than those used for renal calculi. However few drugs are used which act because of their mufattit (lithotryptic) property and not because of hot or cold temperament. There are some drugs which are more useful in renal calculi than bladder calculi such has hajrul yahud. Few drugs are beneficial in both bladder and renal calculi such as Majoon $a q r a b$. Some drugs do not have the property of nuzj, but a few are mufattit as well as have the property of nuzj like habbulqilqil. Mudiribaul (diuretic) drugs also have mild degree of hararat, which helps the kidneys to absorb the liquid matter. All those drugs which are tezact as diuretics such as Karafs, Badiyan, duqu etc. ${ }^{14}$

\section{CONCLUSION}

After reviewing the literature we can say that management of renal stone is explained in very systemic manner,Unani physician advised plenty of oral fluid in renal stone disease which is very important factor in management of renal stone. In Modern era we know that role of diet is very significant in any kind of disease. Eminent unani scholars wrote in detail about diet in renal stone. Mufattit e hasat and mudir boul advia are used for extraction and removal of stone which will be very effective and safe with less or no side effect to the urinary system.

\section{Conflicts of Interest: Nil}

\section{REFERENCES}

1. B Tudor, A Man, E Mitranovici, A Tudor, "Microbiological study of Urinary calculi in patients with urinary infection" AMT, ACTA MEDICA TRANSILVANICA June 2013;2(2):245-249 ).

2. C. Dimopoulos, A. Gialas, M. Likourinas, G. Androutsos, and A. Kostakopoulos, "Hippocrates: founder and pioneer of urology,". British Journal of Urology, 1980 vol. 52, no. 2, pp. 73-74.

3. E. Poulakou-Rebelakou1, A. Rempelakos, C. Tsiamis, C. Dimopoulos. "I will not cut, even for the stone”: origins of urology in the hippocratic collection IBJUJanuary - February, 2015Vol. 41 (1): 26-29.

4. Ahmad Shafiq, M.A Tariq, Shad "Prevalence of renal calculi, type age and gender, specific in southern Punjab, Pakistan" Professional Med J 2016;23(4): 389-395. www.theprofesional.com 
5. Majoosi AA. Kamilul Sanaah, (Urdu translation by Kantoori GH). Vol-1, 2. New Delhi: IdaraKitabuslShifa; 2010: 1889525-528.

6. Qamri MH. GhinaMuna (Urdu translation by CCRUM). New Delhi: Ministry of Health and Family Welfare, Govt. of India; 2008:

7. Ibne Zohar. Kitab al TaisirFilMudawatwatTadbir. 1st ed. (Urdu translation by CCRUM). New Delhi: Ministry of Health and Family Welfare; 1986: 153-157.

8. Ibn Sina. AL Qanoon Fil Tib, (Urdu translated by Kantoori GH). Vol. II. New Delhi: IdaraKitabulShifa; 2007. 212-215.

9. Kabiruddin, Hakim Muhammad. Al- Iksīr (Urdu). Ejaz Publication House, Delhi, 2003, Vol 2, p-12011220.
10. Arzani A. Tibbe Akbar (Urdu Translation by Husain M). New Delhi: IdaraKitabulShifa; YNM.

11. Razi AMBZ. Al Hawi fit Tib. (Urdu translation by CCRUM). Vol-10 New Delhi: CCRUM, Ministry of Health and Family Welfare, Govt. of India; 2002.

12. ABM Razi. Kitab-ul-Mansoori.12th Edi. New Delhi, CCRUM. Feb.1991; 382-5.

13. Jurjān̄̄, Ismā'īl. Tarjuma-iZakhira-iKhwārzamShāhī (Urdu translation by H. H. Khan). Munshi Naval Kishore Press, Lucknow. 1903 Vol. 2

14. Ibn Rushd. Kitāb Al-Kulliyāt (Urdu). Central Council for Research in Unani Medicine, New Delhi: (1987): 224-227 